\title{
COMPLICATIONS OF RADIAL ARTERY LINES IN THE PAEDIATRIC PATIENT*
}

\author{
Katsuyuki Miyasaka, J.F. Edmonds and A.W. Conn
}

\section{INTRODUCTION}

A MAJOR ADVANCE in the monitoring of critically ill patients occurred with the introduction of long-term indwelling arterial lines.

This technique permits continuous observation of arterial blood pressure as well as providing easy access to arterial blood for serial sampling. Its value is so obvious that the insertion of an arterial cannula has almost become routine for sick patients of any age. ${ }^{1-4}$ For anatomical reasons, the radial artery is usually the "artery of choice." From our own observations and from published reports, it is apparent that significant morbidity may occur ${ }^{3,5-10}$ with an occasional major catastrophe. ${ }^{11-14}$

This study was designed to document the incidence of complications in a prospective series, following insertion of radial artery lines in paediatric patients. Radial Artery (R.A.) cannulae were inserted either in the operating room or in the intensive care unit. In the O.R. a cutdown procedure was performed to identify the radial artery and the cannula was inserted under direct vision. The arteries were not ligated distal to the insertion of the cannula. In the I.C.U. the cannulae were inserted by a percutaneous technique. All radial artery lines were maintained patent by a constant infusion of dilute heparin solution. Following removal of the cannulae all patients were checked for a period of ten days to determine the presence or absence of R.A. obstruction. If R.A. obstruction occurred, the patients were followed until recannalization was determined.

This paper deals with 53 sites (47 patients) who had R.A. cannulae inserted during a six-month period between January and June 1974. The majority of these cases (50) followed cardiovascular surgery, and 81 per cent were performed using the left radial artery. There was no significant difference in the number inserted using a cut-down procedure ( 27 cases) as opposed to those with a percutaneous technique ( 26 cases) or in the sex incidence ( $\mathrm{M}: \mathrm{F} 30: 23$ ).

The cannula most commonly used was the Angiocath \#20 (used in 50 cases); other cannulae used were Angiocath \#18 and one Medicut $\uparrow \# 20$.

The mean duration of cannulation was 3.6 days. The results of this series are presented in the accompanying figures.

Table I divides the complications of radial artery lines into three main types, namely skin lesions, radial artery obstruction, and non-elective removal. Nonelective removal of cannulae was carried out wherever withdrawal of blood from the cannula became difficult. Cannulae were never flushed to remove clotted blood

-From: Intensive Care Unit, The Hospital for Sick Children, Department of Anaesthesia, University of Toronto.

-Angiocath@ Deser Pharmaceutical Company Incorporated.

† Medicut@ Sherwood Medical Industries Incorporated. 
TABLE I

Complications of Radial Artery lines

\begin{tabular}{lccc}
\hline \hline & $\begin{array}{c}\text { Percutaneous } \\
\text { technique }\end{array}$ & Cut-down & Totals \\
\hline 1. Skin lesions & & & 18 cases $(34 \%)$ \\
$\quad$ (a) Mild-Colour change only & 4 & 8 & \\
$\quad$ (b) Moderate-Pain, Induration & 1 & 4 & \\
$\quad$ (c) Severe-Necrosis & - & 1 & 27 cases $(51 \%)$ \\
2. Radial artery obstruction & 8 & 19 & 6 cases $(11 \%)$ \\
3. Non-elective removal & & & \\
$\quad$ (a) Accidental & 1 case & & \\
(b) Blood-withdrawal problems & 5 cases &
\end{tabular}

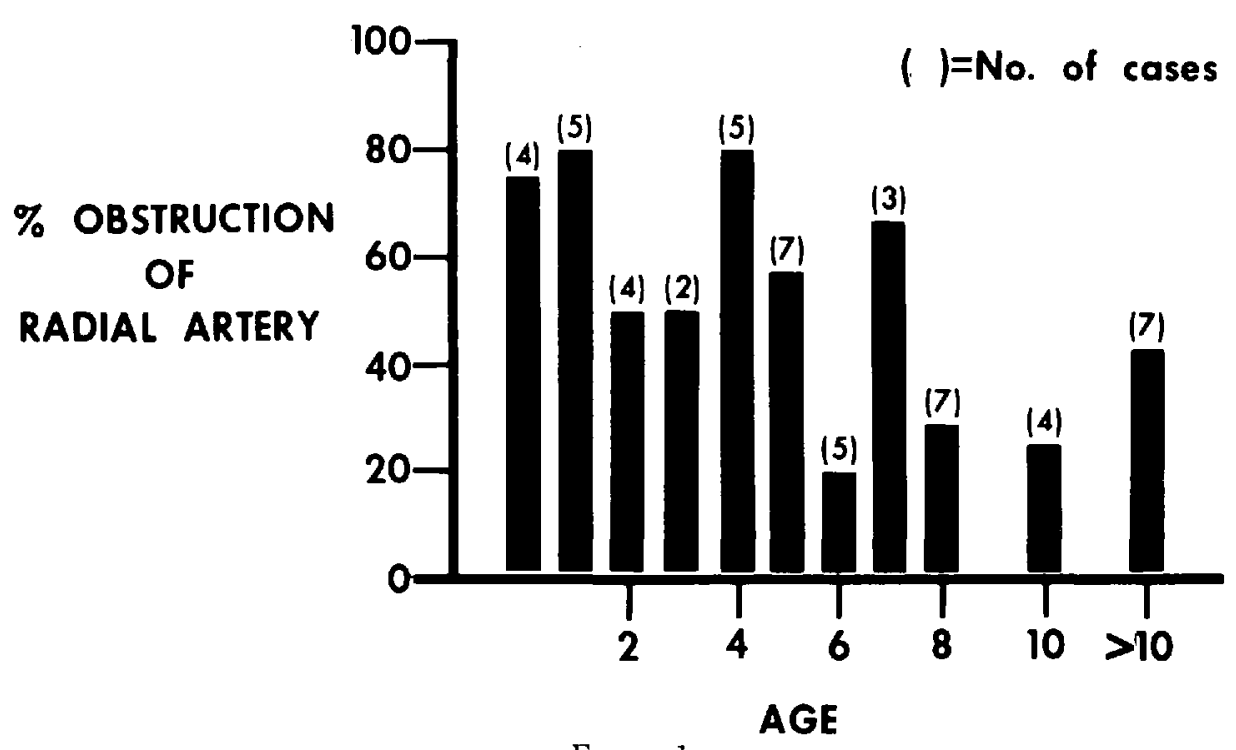

Figure 1

from the cannula because of the danger of injecting particulate material into the arterial system. In one case the line was accidentally removed.

The skin of the arm was examined every eight hours while the cannulae were in position to observe changes in perfusion of the limb. As soon as any colour change was observed, denoting a perfusion problem in that limb, the cannula was removed. There were skin lesions noted in 18 cases ( 34 per cent of the series) and in one case there was an area of skin necrosis on the anterior aspect of the lower arm, proximal to the site of cannula insertion.

To determine the patency of the radial artery following removal of the cannula, a Doppler flow detector was used along the path of the radial artery. This observation was carried out twice on the day of removal and on a daily basis until ten days after cannula removal. If obstruction of the radial artery was detected, this observation was continued until recannalization had occurred. A total of 27 cases were noted to have periods of radial artery obstruction. Figure 1 correlates the age of the patient with the percentage in that age group whose radial arteries became ob-

$\Varangle$ Parks Electronics Lab, Oregon. 

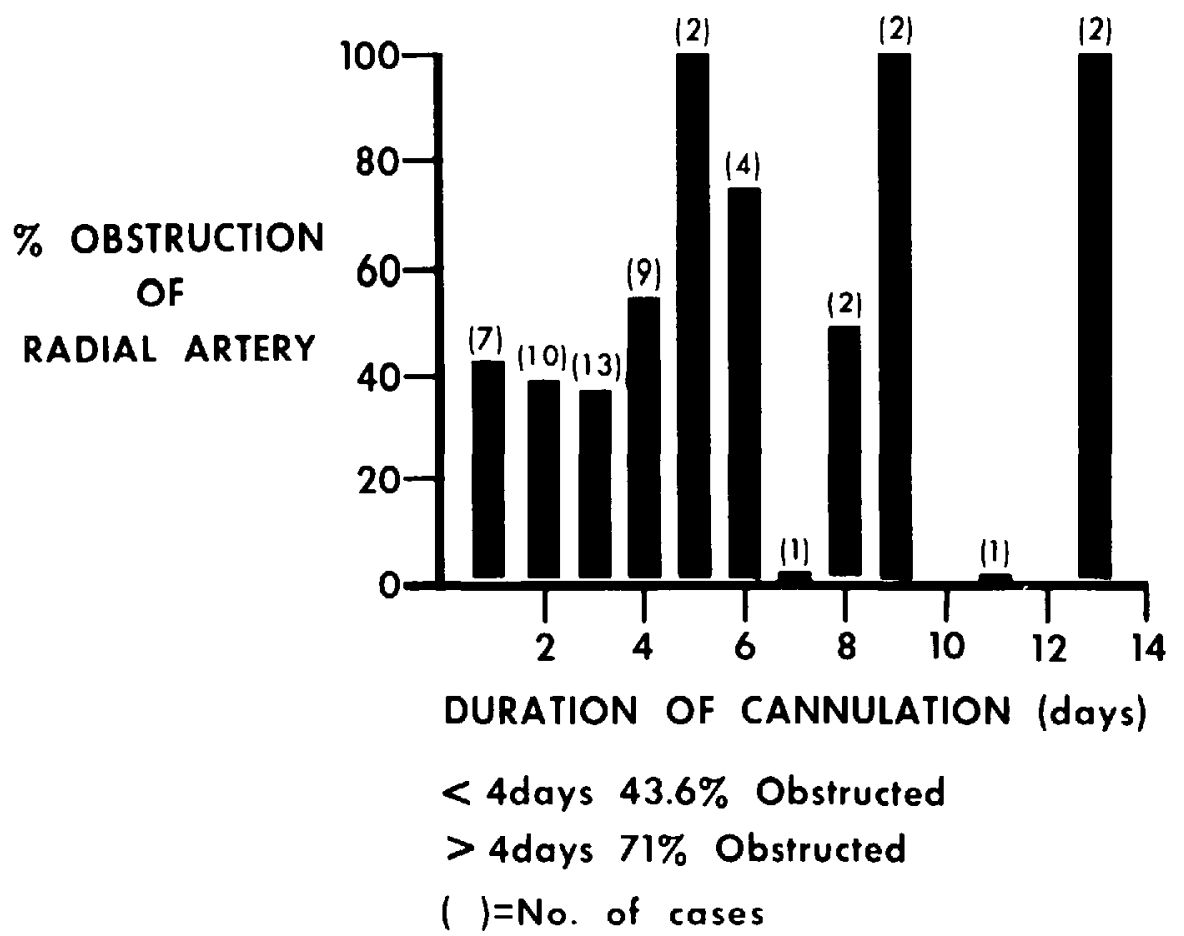

Figure 2

structed. It will be noted that in the younger age group there is a much higher incidence of obstruction of the radial artery than in those over five years of age.

Figure 2 shows that although short-term cannulation ( $<4$ days) does not guarantee that there will be no obstruction of the artery following removal, there is a very high incidence ( 71 per cent) of obstruction in those cases who were cannulated for periods over four days. All obstructed vessels eventually recannalized and most were recannalized within 7 to 14 days. It is of interest to note that those lines inserted using a percutaneous technique all recannalized within ten days of removal and Figure 3 shows that those inserted using a cut-down procedure took longer to recannalize than those inserted using a percutaneous technique. This series could find no correlation between the duration of cannulation and the duration of obstruction of the artery following cannula removal (Figure 4).

In summary, radial artery cannulae were inserted at 53 sites ( 47 patients) with a subsequent high incidence of skin complications ( 34 per cent) and radial artery obstruction ( 51 per cent). Important factors predisposing to radial artery obstruction were:

(a) the age of the patient (66 per cent under five years versus 34.4 per cent over five years),

(b) insertion technique ( 70 per cent with cutdown versus 31 per cent with percutaneous insertion),

(c) duration of cannulation (71.4 per cent over four days and 43.6 per cent under four days). 


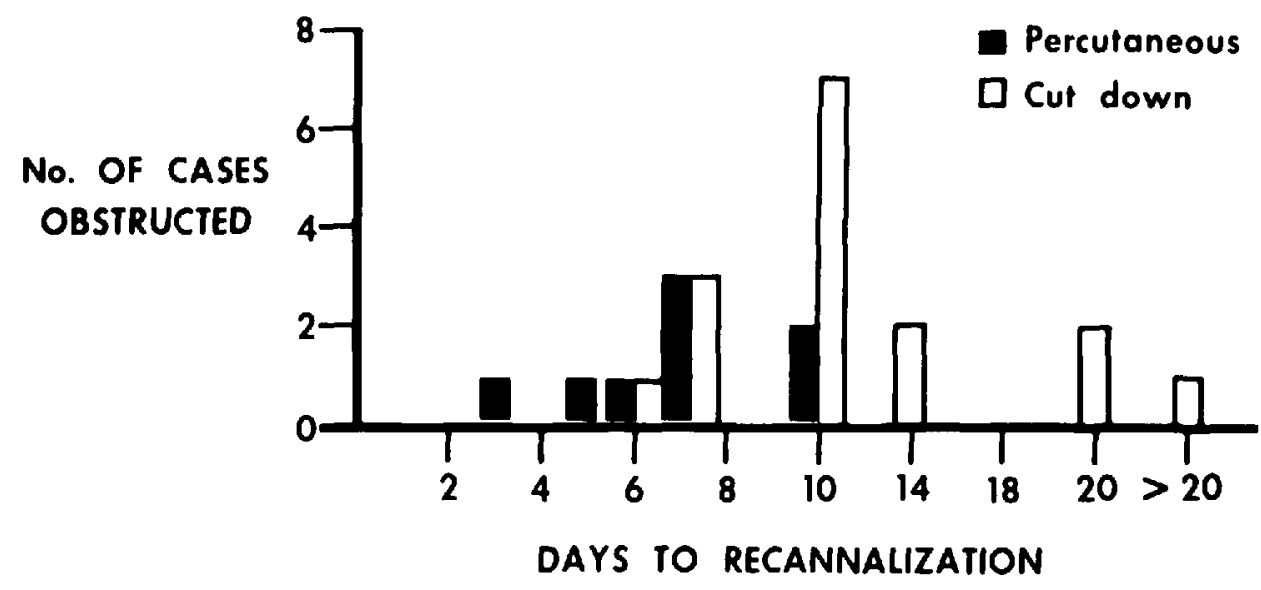

Figure 3

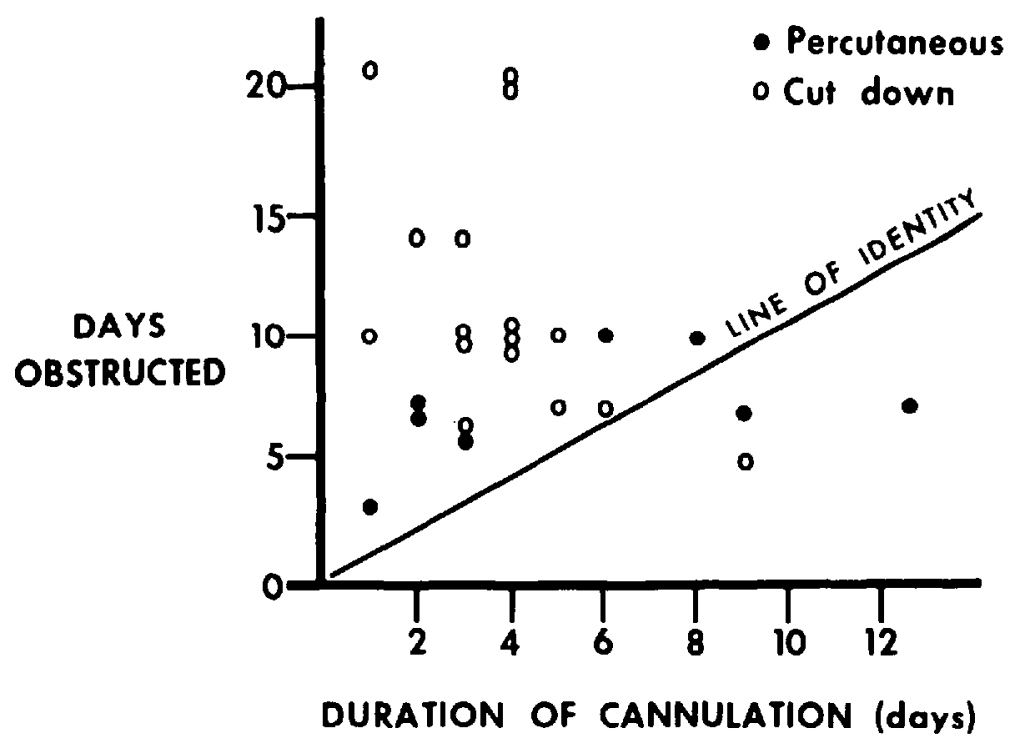

FIGURE 4

No patient, either in this small series or during five years previous experience developed major infection at the site, or serious vascular impairment to the fingers or hand. Reported cases of gangrene have usually followed the insertion of R.A. line into a circulation previously compromised by vascular injury or disease, ${ }^{12,15}$ failure to perform pre-insertion tests for the presence of a complete palmar arch with ulnar dominance and adequate collaterals, ${ }^{16-19}$ delayed removal of the cannula when transient ischaemia is noted and failure to perform an immediate embolectomy when ischaemic changes persist. Therefore it is suggested that when proper precautions are taken, this monitoring technique is amply justified by its value, despite a high incidence of minor morbidity. 


\section{RÉSUMÉ}

Les auteurs ont étudié de façon prospective les complications survenant après canulation de l'artère radiale chez 47 enfants. Ils ont noté une incidence élevée de complications cutanées - 34 pour cent des cas de mineures à modérées - sauf pour un cas de nécrose cutanée après canulation par dissection, et un taux élevé d'obstruction de l'artère ( 51 pour cent des cas). Les artères se sont éventuellement toutes recanalisées dans un court délai. Les facteurs favorisant l'obstruction de l'artère étaient:

a) l'age des enfants ( 66 pour cent d'obstruction chez les enfants de moins de 5 ans et 34 pour cent chez ceux de plus de 5 ans).

b) la technique de canulation ( 70 pour cent d'obstruction suivant une technique avec dissection et 31 pour cent par voie percutanée).

c) la durée de canulation ( 71 pour cent d'obstruction suivant une canulation de plus de 4 jours et 43 pour cent si moins de 4 jours).

Les auteurs proposent les précautions suivantes: vérification des arcades palmaires avant la canulation, non canulation en présence de mauvaise vascularisation do la main par traumatisme ou par maladie, enlèvement immédiat. de la canule en cas d'apparition de phénomènes ischémiques passagers, et embolectomie immédiate en cas d'isoémie permanente; ils concluent que si ces précautions sont prises, cette forme de monitoring est parfaitement justifiée malgré une incidence élevée de complications mineures.

\section{REFERENCES}

1. Adams, J.M., \& Rudolph, A.J. Use of indwelling R.A. catheters in neonates. Paediatrics 55: 261-265 (1975).

2. Brown, A.E., Sweeney, D.B., \& Lumley, J. Percutaneous radial artery cannulation. Anaesthesia 24: 532-536 (1969).

3. BedFond, R.F. \& WOLlMan, H. Complications of percutaneous radial artery cannulation: an objective prospective study in man. Anesthesiology 38: 228-236 (1973).

4. Gardnef, R.M., Schwartz, R., Wong, H.C., \& Burke, J.P. Percutaneous indwelling radial artery catheters for monitoring cardiovascular function. The New England Joumal of Medicine 290: 1227-1231 (1974).

5. Montensen, J.D. Clinical sequelae from arterial needle puncture, cannulation and incision. Circulation 35: 1118-1123 (1967).

6. SamaAn, H.A. The hazards of radial artery pressure monitoring. J. Cardiovasc. Surg, 12 : 342-347 (1971).

7. Downs, J.B., Fackstein, A.D., \& KLein, E.F., Jr., et al. Hazards of radial artery catheterization. Anesthesiology 38: 283-286 (1973).

8. Zinner, S.H., Denny-Brown, B.C., \& Braun, P. et al. Risk of infection with intravenous indwelling catheters: effect of application of antibiotic ointment. J. Infect. Dis. 120:616619 (1969).

9. Stamm, W.E., Colella, J.J., Anderson, R.L., \& Dixon, R.E. Indwelling arterial catheters as a source of nosocomial bacteremia. New England Journal of Medicine 292: 1099-1102 (1975).

10. Jounson, R.W. A complication of radial artery cannulation. Anesthesiology 40: 598-600 (1974).

11. GaAn, D., Brewis, R.A.L., Mallick, N.P., Seedat, Y.K., \& Mahoney, M.P. Cerebral damage from declotting Scribner shunts. The Lancet, 77-79 (1969).

12. Katz, A.M., Birnbaum, M., Moylan, J., \& Pellett, J. Gangrene of the hand and forearm: a complication of radial artery cannulation. Critical Care Medicine 2: 270-272 (1974).

13. Lowenstein, E., Litthe, J.W. III, \& Lo, H.H. Prevention of cerebral embolization from flushing radial artery cannulas. New England Journal of Medicine 285: 1414-1415 (1971). 
14. SamaAn, H.A. The hazards of radial artery pressure monitoring. J. Cardiovasc. Surg. 12: 342-347 (1971).

15. Он, T.E. \& Davis, N.J. R.A. cannulation. Anaes. Int. Care 3: 12-18 (1975).

16. ALLEN, E.V Thromboangitis obliterans: methods of diagnosis of chronic occlusive arterial lesions distal to the wrist with illustrative cases. Am. J. Med. Sci. 178: 237-244 (1929).

17. BRoDSKY, J.B. Simple method to determine patency of ulnar artery intra-operatively prior to R.A. cannulation. Anaesthesiology 42:626-627 (1975).

18. Ramanathan, S., Chalon, J., \& Turndorf, H. Determining patency of Palmar arches by retrograde radial pulsation. Anaesthesiology 42: 756-757 (1975).

19. Mozersky, D.J., Buckley, C.J., Hagoon, C.O., Capps, W.F., \& Dannemiller, F.J. Ultrasonic evaluation of the Palmar circulation. Am. J. Surg. 126: 810-812 (1974). 